\title{
Coupled trace element mobilisation and strain softening in quartz during retrograde fluid infiltration in dry granulite protoliths
}

\author{
Bjørn Eske Sørensen · Rune B. Larsen
}

Received: 28 February 2008/ Accepted: 2 July 2008/Published online: 23 July 2008

(C) The Author(s) 2008

\begin{abstract}
This study focuses on the retrograde rheological and chemical evolution of quartz and the behaviour of quartzites during retrograde metamorphism following dry high grade metamorphism at $750^{\circ} \mathrm{C}, 7 \mathrm{kbar}$. SEM-CL and LA-HR-ICP-MS are applied to document quartz texture and chemistry, respectively. Four generations of quartz were distinguished by SEM-CL; Qz1, Qz2, Qz3 and Qz4. Qz1, brecciated and partly dissolved old grains, is enriched in $\mathrm{B}$, $\mathrm{Al}$ and $\mathrm{Ti}$ when compared with the other types. Qz2, formed during brecciation and partial dissolution of Qz1, has low $\mathrm{Al}$ contents $(<50 \mathrm{ppm})$ but, due to rutile inclusions, variable $\mathrm{Ti}$ contents when occurring in amphibolite (210-10 ppm) but more consistent values when occurring in quartzites (peak value $32 \mathrm{ppm}$ ). Qz3, dark grey luminescent quartz forming fluid migration channels (fluid pathways), has $\mathrm{Ti}<5 \mathrm{ppm}$ and $\mathrm{Al}$ contents below $10 \mathrm{ppm}$ and $\mathrm{B}<1 \mathrm{ppm}$. Qz4, comprises are group of quartz later than Qz3 filling micron thick cracks and pods with very low luminescent quartz, i.e. darker than Qz3. The textural and chemical evolution of quartz in our study is explained by two major influxes of aqueous fluids during regional uplift and retrogression. They facilitated rehydration and recrystallisation in the otherwise dry high grade quartzites. The first introduction of aqueous fluids
\end{abstract}

Communicated by J. Hoefs.

Electronic supplementary material The online version of this article (doi:10.1007/s00410-008-0326-9) contains supplementary material, which is available to authorized users.

B. E. Sørensen $(\square) \cdot$ R. B. Larsen

Department of Geology,

Norwegian University of Science and Technology,

Sem seelands veg 1, 7491 Trondheim, Norway

e-mail: bjorn.sorensen@ntnu.no

R. B. Larsen

e-mail: rune.larsen@ntnu.no was associated with brecciation of the high grade quartz (Qz1) and dissolution/precipitation of quartz (Qz2). Ti in quartz geothermometry (Wark and Watson, Contrib Mineral Petrol 152(6):637-652) gives $626^{\circ} \mathrm{C}$ in agreement with the retrograde PT-path deduced from phase diagrams. Later fluid influx associated with scapolitisation of amphibolite caused localised recrystallisation (Qz3) and alteration of biotite to muscovite along mm-wide fluid migration channels. During subsequent deformation, Qz3 deformed plastically and recovered by subgrain rotation recrystallisation (SGR), resulting in a reduction of grain size, whereas Qz1 quartz formed micro faults. Qz2 was plastic but did not experience SGR to the same degree as Qz3 quartz. Increased plasticity and recovery rates most likely relate to an increased $\mathrm{H}_{2} \mathrm{O}$ fugacity and the depletion in trace elements of the quartz lattice by promoting strain softening processes dislocation climb and recovery.

Keywords Quartz - Quartz rheology · Hydrolytic weakening - Trace elements - High-purity quartz . Fluid flow - Shear zone - Strain localisation . Strain softening $\cdot$ Strain hardening $\cdot$ Mass transfer

\section{Introduction}

The aim of our study is to unravel the retrograde behaviour of high grade quartz and quartzites, under the influence of infiltrating fluids and shear zone deformation. At upper crustal conditions, quartzites are some of the softest rocks in the continental crust hence, acting as decollement zones during tectonic events (e.g. Tullis 2002). Due to their relatively simple chemistry and high preservation extent, quartzites provide new information on fluid migration and regional mass balance properties during shear zone processes. 
The strength of quartz single crystals and quartz aggregates is lowered by an order of magnitude by the addition of $\mathrm{H}_{2} \mathrm{O}$ (e.g. Griggs and Blacic 1965; Kronenberg 1994; Kronenberg et al. 1986; Post and Tullis 1998). Of several parameters in the chemical environment $\left(\mathrm{aH}^{+}\right.$, $\mathrm{fH}_{2} \mathrm{O}$; aOH ${ }^{-}$), only $\mathrm{fH}_{2} \mathrm{O}$ has significant effects on creep strength as well as annealing rate (Post et al. 1996). Strain induced grain boundary migration and dislocation climb is enhanced by $\mathrm{H}_{2} \mathrm{O}$. Hence, $\mathrm{H}_{2} \mathrm{O}$ promotes recrystallisation accommodated dislocation creep and climb accommodated creep (Post et al. 1996).

Important for the rheology of quartzites is their ability to equilibrate with ambient $\mathrm{H}_{2} \mathrm{O}$ fugacities. Assuming infinite grain boundary diffusion all grain sizes from 10 microns to $1 \mathrm{~mm}$ would re-equilibrate with the ambient $\mathrm{H}_{2} \mathrm{O}$ fugacity within $1 \mathrm{Ma}$ at $\mathrm{T}>450^{\circ} \mathrm{C}$, whereas at $300-350^{\circ} \mathrm{C}$ large grain sizes would require re-equilibration times in excess of 100 Ma., i.e. much longer than normally assumed during uplift (Post and Tullis 1998).

Experiments document reduction in the dislocation and trace elements contents of quartz during multiple recrystallisations under conditions corresponding to greenshist facies (Armington and Balascio 1984).

Cathodoluminescence (CL) is generated by defects in the quartz lattice, including lattice bound trace elements (e.g. Goetze et al. 2001; Müller et al. 2003; Goetze et al. 2004, 2005). Several studies document mobilisation of trace elements during recrystallisation using SEM-CL and trace element analysis in magmatic (e.g. Müller et al. 2002; Larsen 2004; Jacamon 2006) and vein quartz (Van den Kerkhof et al. 2004; Landtwing and Pettke 2005).

Our study relies on SEM-CL to interpret the complex recrystallisation behaviour in quartzites, quartz rich gneisses and quartz veins from the Bamble sector. We demonstrate the intimate relationship between fluids, quartz recrystallisation, rheology and purification as a function of changing physiochemical conditions during the exhumation of the Bamble mega shear zone complex.

\section{Geological setting}

The Bamble sector comprises exceptionally well preserved high grade amphibolite-granulite facies rocks (Touret 1968). The peak PT-conditions were c. $850^{\circ} \mathrm{C}$ in the HT granulite facies zone at Arendal, and tapering towards lower $T$ in a thermal dome pattern with peak $P$ of roughly 6-7 kb (Nijland and Maijer 1993) (Fig. 1).

Fluid inclusion studies document $\mathrm{CO}_{2}$ dominated fluids in amphibolite lithologies, and $\mathrm{CO}_{2}+$ brines in more siliceous gneisses during peak metamorphic conditions (Touret 1971); conclusion that is supported by fluid modelling using the iron-titanium oxygen barometer (Harlov 2000).

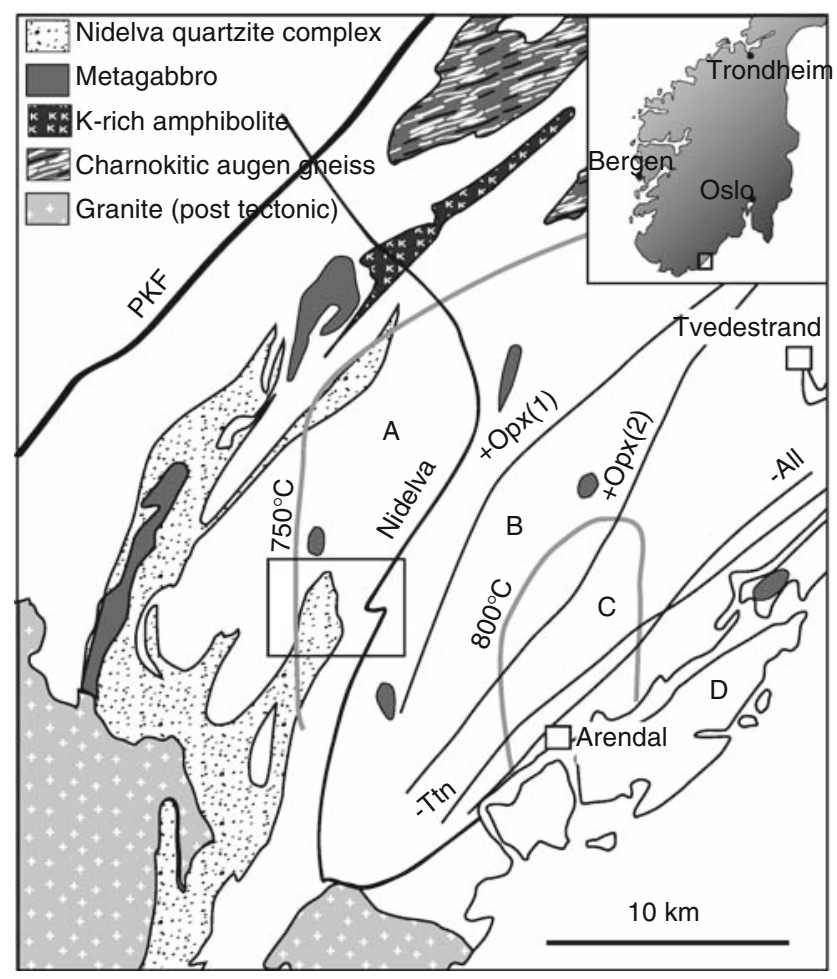

Fig. 1 Overview map of the Bamble Sector showing the most important rock units and the metamorphic zones in the Bamble sector. Square denotes the position of the study area shown in Fig. 2. Modified from Nijland et al. (1998)

Fluid related alteration follows a rhombohedral network of shear zones and faults, associated with exhumation and possibly also extensional collapse of the Sveconorwegian orogen (Touret 1968). The absence of retrograde aluminous silicate assemblages implies high alkali-chloride activities in the retrograde fluids (Touret 1968). Brine-rich fluid inclusions are documented together with the alteration assemblages (e.g. Touret 1985; Nijland et al. 1998; Nijland and Touret 2001).

The retrograde PT-paths vary systematically across the Bamble sector with a steep retrograde path in the southernmost part, followed by isobaric cooling in the southeast and a slight pressure increase in the north (Knudsen 1996). However the P-T estimates are uncertain (Knudsen 1996).

Fluid inclusion data and mineral parageneses define the following cooling and uplift path of the Froland area (Sørensen 2007):

1. C. $626^{\circ} \mathrm{C}$ and $7 \mathrm{~kb}$. The total fluid composition for this stage: $\mathrm{XCO}_{2}=0.30, \mathrm{XH}_{2} \mathrm{O}=0.62, \mathrm{XNaCl}=0.08$ (30 wt $\% \mathrm{NaCl}$ in the aqueous phase). $\mathrm{XCO}_{2}$ decrease rapidly with falling $T$.

2. A shift from potassic-sodic to sodic-calcic alteration inferred from mineral assemblages described by Nijland et al. (1993a). P-T conditions $450-550^{\circ} \mathrm{C}$ and min $P$ of $4.5 \mathrm{~kb}$. 
3. Uplift path recorded by fluid inclusions isochores in quartz: $300-400^{\circ} \mathrm{C}$ associated with a P-drop from 5-7 to $2-3 \mathrm{~kb}$.

4. Coexisting prehnite and pumpelyite + fluid inclusions at $2-3 \mathrm{~kb}$ and $175-280^{\circ} \mathrm{C}$ (Touret and Olsen 1985; Nijland et al. 1993a).

\section{Methodology}

Sample preparation

The textural relations between the different quartz types are typically present in a single hand specimen. Textural relations were studied macroscopically on polished hand samples and microscopically in thin sections.

Thin $(30 \mu \mathrm{m})$ and thick sections $(200 \mu \mathrm{m})$ (for LA-HRICP-MS) were prepared from the same chip to correlate optical and SEM-CL textures in ablated samples.

\section{SEM-CL}

SEM-CL was performed on a low vacuum SEM at the Norwegian University of Science and Technology. The luminescence signal was recorded in greyscale pictures with a Robinson detector under variable pressure conditions $(5-10 \mathrm{~Pa})$ in order to avoid carbon coating.

In most cases a working distance of $20 \mathrm{~mm}$ and an acceleration voltage of $15-20 \mathrm{KV}$ were chosen. A working distance of $30-40 \mathrm{~mm}$ and $30 \mathrm{KV}$ acceleration voltage were applied to map large areas. Beam current was set to the maximum possible at the instrument to achieve good signal, typically this is about $75 \mu \mathrm{A}$.

A mosaic of images was welded in a single picture often covering the entire thin sections. A brief description of the samples used for LA-HR-ICP-MS analysis is given in eAppendix1. Quartz was grouped according to the dominant SEM-CL texture rather than absolute luminescence because SEM contrast conditions commonly change slightly when changing samples.

Supplementary Mono-CL was gathered on representative samples at the Department of Geology, University of Oslo. Spectra were collected at $15 \mathrm{kV}$ acceleration voltage. Collection time, aperture and beam current were adjusted for optimal counting statistics.

\section{LA-HR-ICP-MS}

LA-HR-ICP-MS of quartz was aquired with a standard, double focusing sector field, ICP-MS (Finnigan MAT, ELEMENT1) instrument with a CD-1 option from Finnigan MAT and with an $266 \mathrm{~nm}$ UV-laser from Finnigan MAT/
Spectrum, Berlin, Germany and included the analysis of ${ }^{7} \mathrm{Li}$, ${ }^{9} \mathrm{Be},{ }^{11} \mathrm{~B},{ }^{27} \mathrm{Al},{ }^{55} \mathrm{Mn},{ }^{74} \mathrm{Ge},{ }^{85} \mathrm{Rb},{ }^{88} \mathrm{Sr},{ }^{137} \mathrm{Ba},{ }^{208} \mathrm{~Pb},{ }^{232} \mathrm{Th}$, and ${ }^{238} \mathrm{U}$ in low resolution $(m / \Delta m=300) ;{ }^{23} \mathrm{Na},{ }^{31} \mathrm{P},{ }^{25} \mathrm{Mg}$, ${ }^{47} \mathrm{Ti},{ }^{52} \mathrm{Cr}$, and ${ }^{56} \mathrm{Fe}$ in medium resolution $(m / \Delta m \approx 3500)$ and ${ }^{39} \mathrm{~K}$ in high resolution $(m / \Delta m>8000) .{ }^{29} \mathrm{Si}$ was used as internal standard at low resolution and ${ }^{30} \mathrm{Si}$ was used at medium and high resolution. External calibration was done with international standards: NIST612, NIST614, NIST616, BCS313/1(BAS), RGM-1(USGS), SRM1830, Blank $\mathrm{SiO}_{2}$ and BAM no. $1 \mathrm{SiO}_{2}$ (Federal Institute for Material Research and Testing, Berlin, Germany). Blank $\mathrm{SiO}_{2}$ was used to constrain the detection limits (LOD). LOD's for most elements are $0.2-0.01 \mathrm{ppm}$. Quantification of individual elements was accomplished with calibration curves including several standards. Laser ablation sampling was in $200 \times 200 \mu \mathrm{m}$ raster or smaller. Detailed information about the analytical conditions, recalculation and statistical treatment of the data is described elsewhere (Flem et al. 2002).

Field observations and sampling

Sampling of quartzitic rocks from the Nidelva Quartzite Complex (NQC) that were intercalated with gneisses and amphibolites was done in Froland in South Norway (Fig. 1, 2) (Nijland et al. 1993b). Amphibolite hosted quartz leucosomes and veins were included for comparison with the quartzites. Samples from five different localities are included (Fig. 2). Representative samples are described in the text. Description and locations of all studied samples are given in eAppendix 1 .

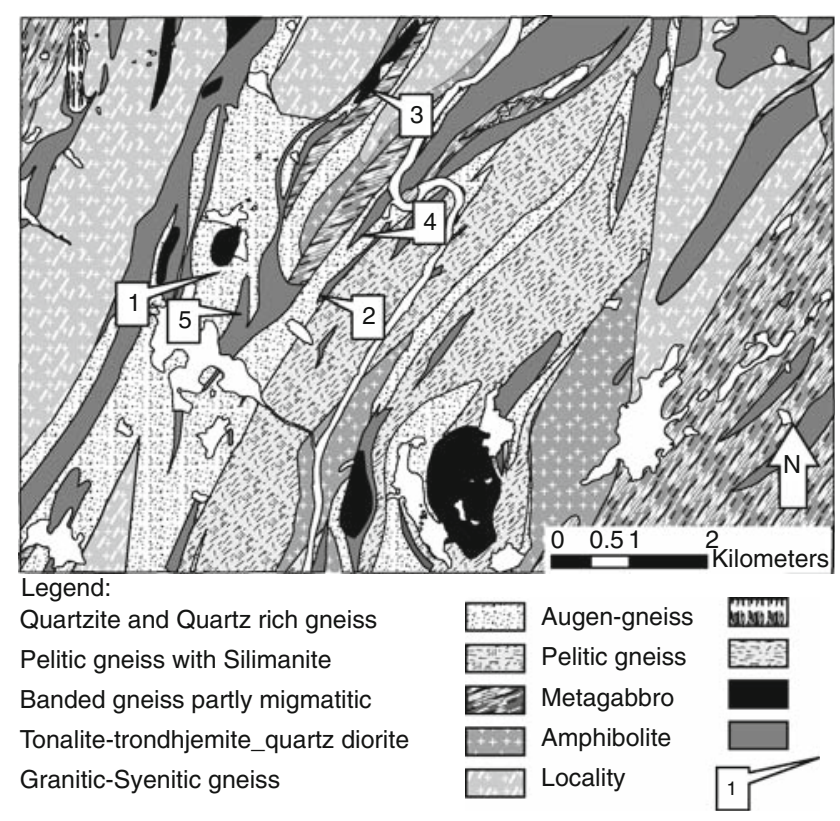

Fig. 2 Detailed map of the investigated area. Modified from Geological Survey of Norway N-50 berggrunnskart 16123 Nelaug and 16114 Arendal 


\section{Results}

SEM-CL and optical textures

\section{Definition of quartz types}

Four main types of quartz (Qz1-Qz4) are defined by SEMCL textures: Qz1, island channel texture; Qz2, light grey;
Qz3, diffuse dark grey channels and Qz4, narrow cracks and pods of non luminescent quartz (see Table 1 below and Fig. 3).

SEM-Mono-Cl was applied to unravel the spectral process behind the luminescence textures (Fig. 3). Two broad peaks dominates all spectra of the different quartz types. Qz1 features a high peak at 350-470 nm (blue-green) related to self-trapped exciton defects, and a peak at

Table 1 Quartz types defined by textures in SEM-CL images

Quartz type Description

Qz1 Bright islands surrounded by darker cracks. Typically partially luminescence quenched

Qz2 Light grey, sometimes with weak oscillatory zoning. Brighter cores and darker rims, approaching the luminescence of type 3

Qz3 Dark grey diffuse fluid channel texture, which follows grain boundaries or cut through grains

Qz4 Narrow cracks and pods of black quartz, crosscutting the other types
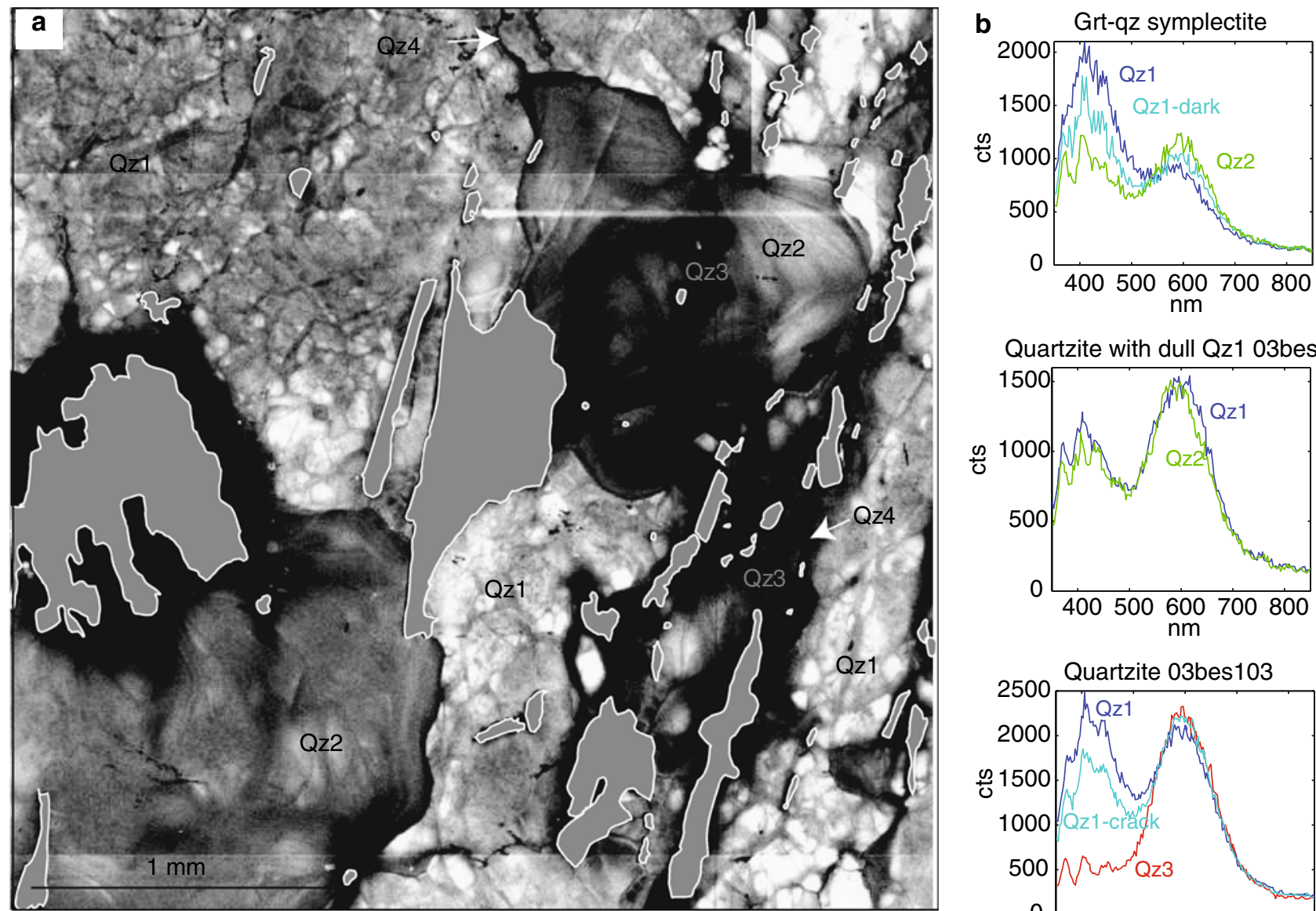

Quartzite with dull Qz1 03bes32
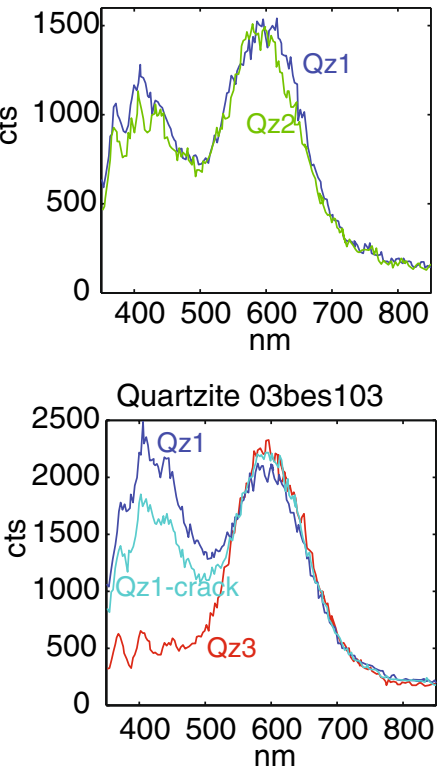

Fig. 3 a Quartz types defined by SEM-CL texture. See text and Table 1 for explanation. b SEM-CL spectra of the studied quartz types, similar scales of wavelength in $\mathrm{nm}$ on the $\mathrm{x}$-axis. Blue lines are Qz1, green Qz2, red Qz3. $Y$-axis is intensity (cps). Two broad peaks at $450 \mathrm{~nm}$ (blue) and at 620-650 nm (orange-red) dominates all the spectra. In garnet quartz symplectites Qz1 included in garnet displays a strong $450 \mathrm{~nm}$ peak, whereas the $620-650 \mathrm{~nm}$ peak is weak. In duller Qz1 the $450 \mathrm{~nm}$ peak decreases relative to the $620-650 \mathrm{~nm}$ peak. The spectra of the duller Qz1(Qz1-dark) lies between the spectra of Qz1 included in the garnet (Qz1) and Qz2. Qz2 and dull Qz1 from quartzite (04bes32) are almost indistinguishable by luminescence intensity and are only distinguished by texture. Qz3 is dominated by one peak at $620-650 \mathrm{~nm}$ and is clearly distinguished from Qz1 in quartzite sample 03bes103. Here, it is also observed that the luminescence of cracks in Qz1 is a mix of Qz3 and Qz1 spectra 
500-670 nm (orange-red) probably related to $\mathrm{H}_{2} \mathrm{O}$ and intrinsic defects (e.g. Goetze et al. 2001). The relative intensity of the two peaks varies within the Qz1. Bright Qz1 is dominated by the $350-470 \mathrm{~nm}$ (blue-green) peak. With progressively lower luminescence and brecciation of Qz1 the 500-670 nm peak is growing relative to the 350$470 \mathrm{~nm}$ peak. Qz2 displays the same luminescence peaks as Qz1 but their relative intensities are changed with the 500-670 nm (orange-red) being more dominant. When luminescence intensities of Qz1 and Qz2 in the SEM-CL images are similar their luminescence spectra are also indistinguishable and they are only distinguished by their intra grain textures. Qz3 only features the $500-670 \mathrm{~nm}$ peak hence the progressive lowering of the greyscale luminescence signal observed in our study reflects the lowering of the blue luminescence.

Fluid inclusions related to quartz types Qz1, Qz2 and Qz3 did not form in quartz veins intersecting quartzites, but are common in quartz veins intersecting amphibolites.

\section{Quartzites}

Quartzites display large textural variations which can be attributed to chemical variations and to recrystallisation during metamorphism. Quartz contents vary on the m-dm scale between $99 \%$ quartz and $79-80 \%$ quartz at locality 1 and $70-95 \%$ quartz at locality 2 . Other minerals include microcline, biotite, and muscovite. Pure quartzites are more coarse-grained than impure varieties. The impure quartzites feature disjunctive cleavage in fibrolite-rich cleavage domains and with white mica intersecting microlithons of quartz and biotite. Both static and dynamic high grade fabrics are cut by narrow deformation zones dominated by cataclasis. Deformation zones are coupled with a distinct bleaching from dark blue grey to lighter and more greenish in response to a paragenetic change from biotite to muscovite bearing assemblages (Fig. 4). Macroscopic lensoid domains of bluish quartz are surrounded by strongly deformed bleached domains in micro-shearzones (Fig. 4). Bluish domains are more coarse-grained and biotite is well preserved with only local alteration to muscovite (Fig. 4). In the SEM-CL pictures, coarse-grained domains comprise Qz1 and Qz2 (Fig. 5). Channel like structures of Qz3 connect grains of biotite that are partially altered to poikiloblastic muscovite (Fig. 5). Biotite is preserved towards and co-exists with Qz1 and Qz2, whereas muscovite is the only mica that co-exists with Qz3 (Fig. 5). Partially altered biotite grains in the coarse-grained domains share contacts with Qz3 channels intersecting Qz2 (Fig. 5).

The quartzites suffer both cataclastic and plastic deformation. Subgrain rotation recrystallisation (SGR) dominates in Qz3 domains causing grain size reduction to $<200 \mu \mathrm{m}$ under the formation of more polygonal grains

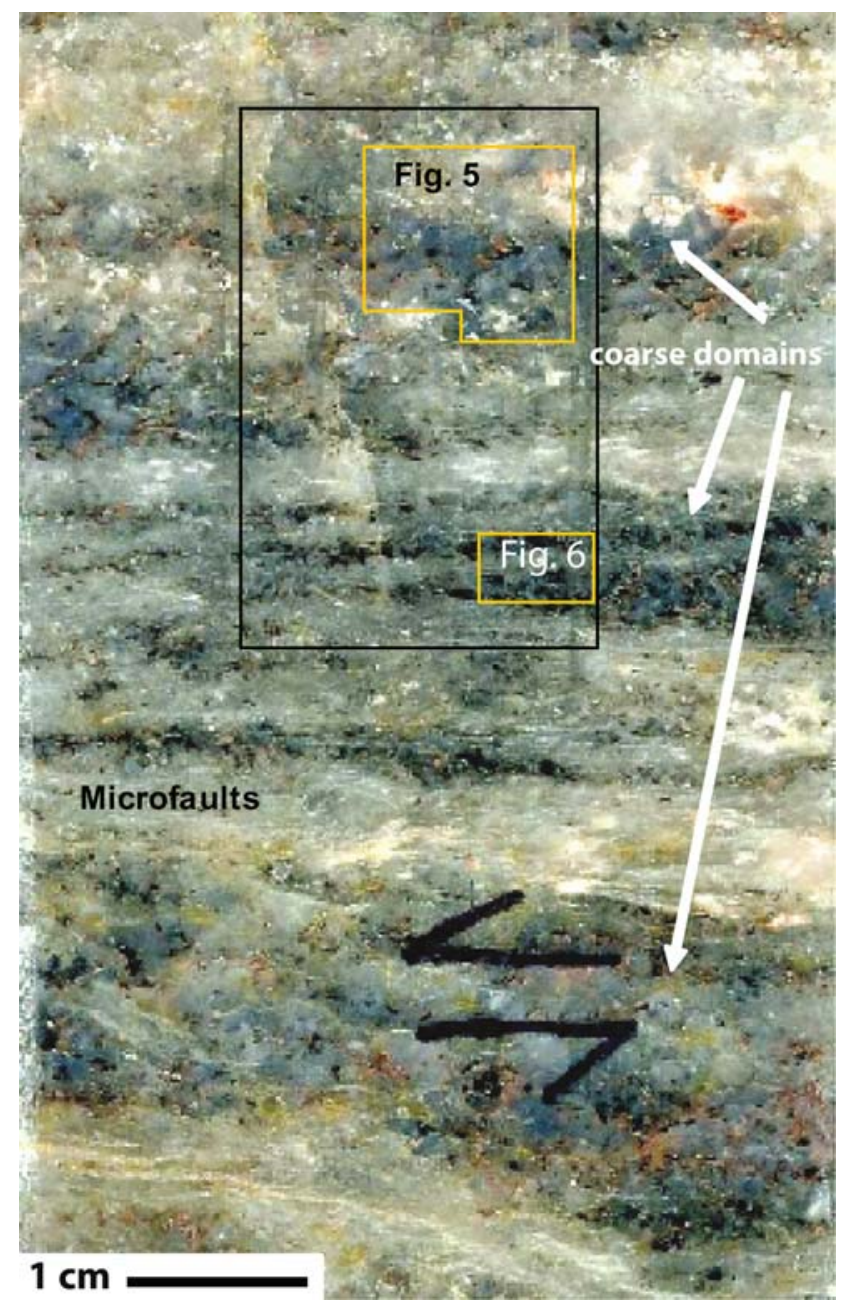

Fig. 4 Polished rock displaying the textural changes in coarsegrained quartzite, subjected to deformation and recrystallisation. Position of the large SEM-CL pictures (Fig. 5, 6) indicated

(Fig. 6). Shape preferred orientation of quartz grains defines an oblique fabric, following a sinistral shear sense (Fig. 6). This corresponds to relative upward movement of the SW block relative to the NE block in the direction of the oblique lineation observed in the field in agreement with a N-S compressive stress-field. Deformation related to SGR in Qz3 textures continues as narrow cataclasite bands when entering other quartz types or disappears (Fig. 6). The SEM-CL intensity of Qz1 increases towards zones where Qz3 is deformed by SGR (Fig. 6).

Distinct differences between the grain boundary geometries are also related to the SEM-CL quartz types. Qz2Qz2 grain boundaries are commonly straight with triple junctions, whereas Qz1-Qz2 grain boundaries are interlobate-lobate with pinning, window, dragging and "left over grain" microstructures (see e.g. Passchier and Trouw 2005; Jessell 1987 for definition) implying the growth of Qz2 at the expense of Qz1 (Fig. 7a). 
Fig. 5 Optical and SEM-CL textures from 03bes71, locality 1. Image from a more coarsegrained part of the sample dominated by luminescence quenched Qz1, intersected by a network of Qz3 connecting mica grains. Enlargement show the spatial relationship between muscovite (bright interference colours), biotite relics and Qz13. Biotite relics in the optical picture correlate with Qz1, whereas the pure muscovite part of the grain is exposed against Qz3

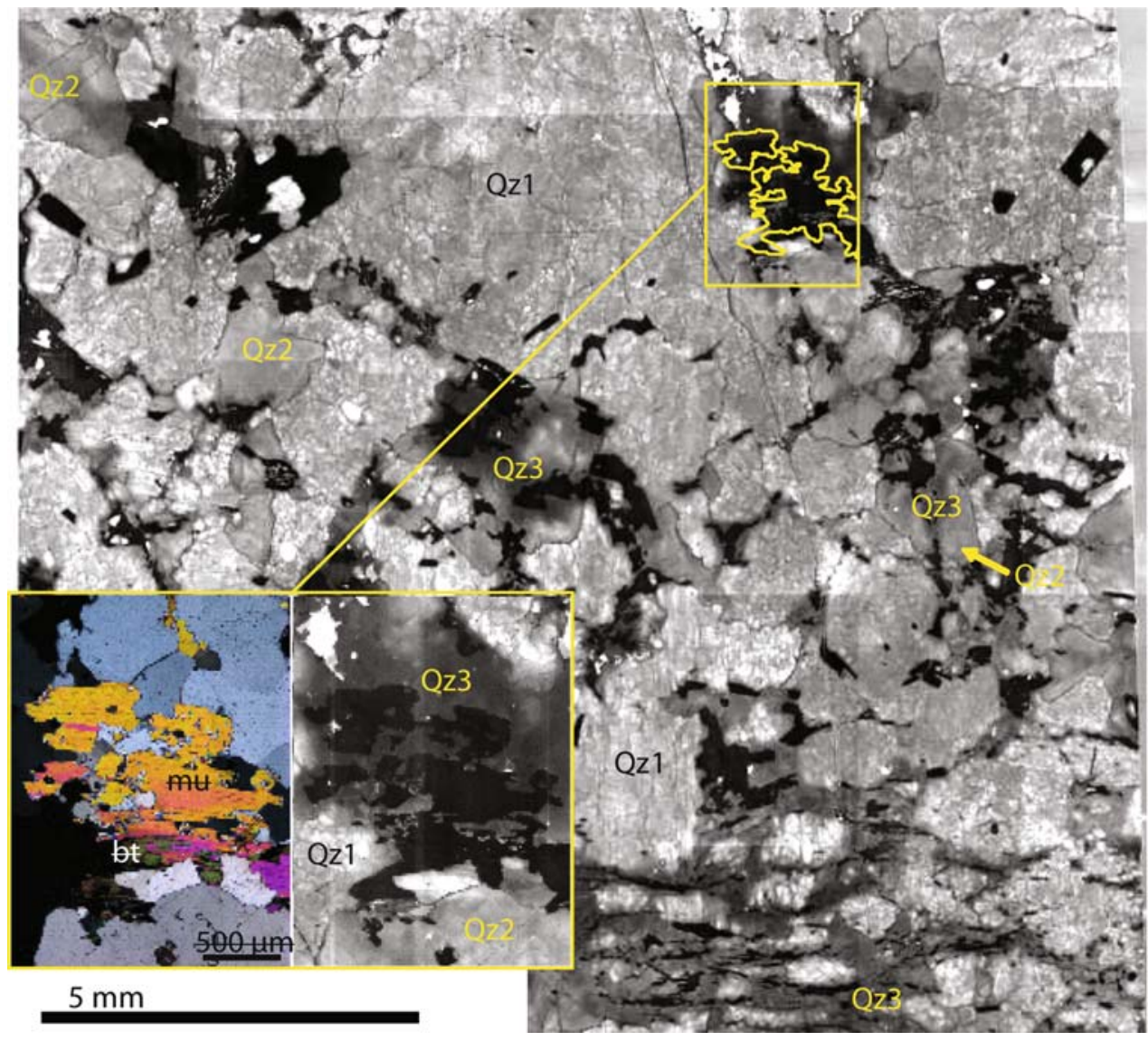

Ilmenite is partly altered to rutile. The proportion of rutile formed at the expense of ilmenite correlates with the amount of Qz2 present (Fig. 7b).

\section{Quartz in amphibolite}

Quartz domains in amphibolite are comprised by several subtypes including garnet quartz symplectites, rose quartz veins, and quartz veins associated with biotite and potassic alteration of amphibolite and quartz veins associated with scapolitisation of amphibolite.

Garnet quartz symplectites mainly comprising blue quartz similar to bluish quartz in the quartzites, garnet and plagioclase occurs in garnet quartz symplectites in garnet amphibolite at locality 3 . They are interpreted as partial melts in the amphibolite. Ilmenite and chlorapatite are common in the garnet quartz symplectites that also carry $\mathrm{CO}_{2}$ fluid inclusions (Sørensen 2007). Quartz comprises bright islands surrounded by cracks with less luminescent quartz (Qz1) and subsidiary Qz2. Qz1 is brecciated with Qz2 like cement (Fig. 8a). Well preserved Qz1 occur as bright inclusions in garnet in the garnet quartz symplectites (Fig. 8a).

Rose quartz veins featuring shades of pink, violet and blue, are exposed in metagabbro. They co-exist with the prograde metamorphic assemblage in garnet amphibolites comprising almandine rich garnet, tschermakitic hornblende, plagioclase (An30) and ilmenite.

Lowering of luminescence is weak and primarily limited to grain boundaries (Fig. 8b). Qz2 is absent but the island texture defining Qz1 is also common (Fig. 8b). Fractured grains of Qz1 are intersected by non luminescent quartz (Qz4) in micron thick trans- and circum-granular cracks (Fig. 8). Qz4 was not included in the LA-HR-ICP-MS analysis because the high density of mineral and fluid inclusions inhibited unbiased analysis. SEM-CL images of rose quartz veins in amphibolite have the highest luminescence of all the studied samples.

Quartz veins associated with potassic alteration of amphibolite are common throughout the area. The potassic alteration is revealed by the introduction of biotite in the amphibolites and formation of new amphiboles and plagioclase. The colour of the amphibole and biotite associated with the potassic alteration varies from dark black amphibole and biotite to light green amphibole and light brown biotite (all field colours). A suite of the quartz vein was investigated by SEM-CL. The quartz veins have the same main quartz types as the quartzites, but their relative proportion and luminescence intensity varies. 

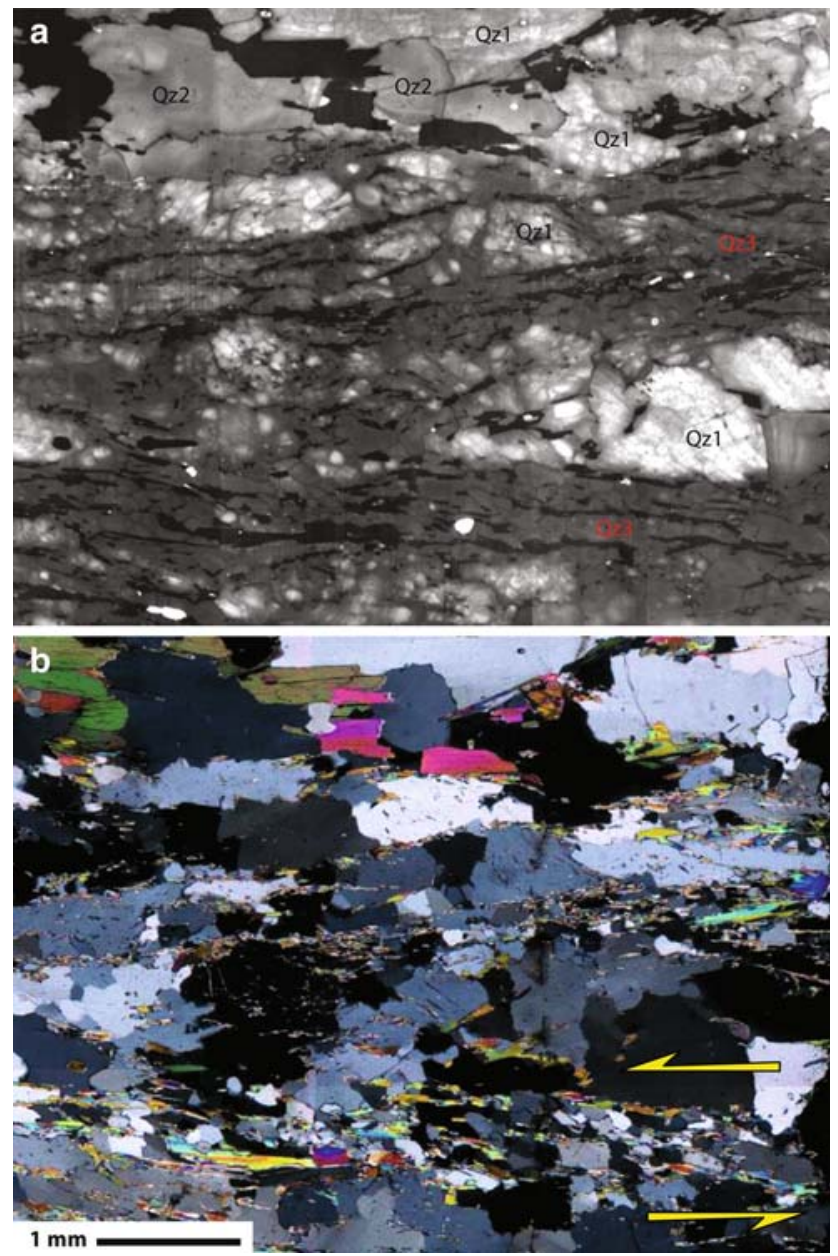

Fig. 6 SEM-CL and optical textures from 03bes71 exposing the intimate relationship between recrystallisation revealed in the SEMCL image and different deformation styles seen in the optical image. a SEM-CL image. b Optical image of the same region. Note that SGR optical textures between the yellow arrows occur only in connection with Qz3 in the SEM-CL image

Quartz veins associated with blackish amphibole and biotite are dominated by Qz1 and Qz2 with only subordinary amounts of Qz3 and Qz4 (Fig. 9a). Optically Qz1 commonly comprises a chessboard texture of subgrains, whereas Qz2 has more even extinction pattern (Fig. 9b). The chessboard microstructure is partly overprinted by basal subgrain microstructures relating to an increase in the luminescence intensity (Fig. 9a, b). Qz2 is coarse-grained and features coarse rutile needles visible at 100 times magnification, whereas rutile needles in Qz1 are much finer and only visible at 500 times magnification.

With increasing bleaching of amphibole and biotite the vein-quartz becomes less luminescent and Qz1 and Qz2 are close in their luminescence intensity and are only differentiated by faint remnants of their SEM-CL microstructures (Fig. 9c). On the contrary, Qz3 is clearly distinguished (Fig. 9c).
Quartz-scapolite veins are generally low luminescent and are dominated by Qz3 and Qz4 (Fig. 10). Some Qz3 is homogeneous in both optical and SEM-Cl images, whereas some Qz3 including subgrains is more luminescent (Fig. 10). Both Qz3 subtypes are intersected by micron thick irregular cracks of Qz4, with a high abundance of solid calcite inclusions and calcite bearing fluid inclusions (Fig. 10).

\section{Chemical evolution of quartz}

A wide range of trace elements were measured, but only Ti, $\mathrm{Al}$, $\mathrm{B}$ and $\mathrm{K}$ occur in significant amounts and will be discussed here (see eA1 for full analysis results).

A plot of $\mathrm{Ti}$ versus $\mathrm{Al}$ shows with bubble sizes from the B-content displays the chemical evolution of quartz through the progressive recrystallisation from Qz1-Qz3 (Fig. 11a). Qz1 represents a wide compositional range from 50 to several hundreds ppm. At closer inspection, two groups are identified when both $\mathrm{B}, \mathrm{Ti}$ and $\mathrm{Al}$ are considered (Fig. 11a). Peak Al contents occur in rose quartz only (Fig. 11d), whereas garnet quartz symplectites and quartz veins have much lower contents of both $\mathrm{B}$ and $\mathrm{Al}$ (Fig. 11d). Taking the other quartz types the typical $\mathrm{Al}$ contents are $15 \mathrm{ppm}$ (Fig. 11d). In Al rich samples from quartz in amphibolite settings $\mathrm{B}$ and $\mathrm{Al}$ are linearly correlated (Fig. 11b) and the slope of the trend line perfectly matches the $\mathrm{B} / \mathrm{Al}$ ratio of dumortierite $\left(\mathrm{Al}_{6.5-7}\left(\mathrm{BO}_{3}\right)\right.$ $\left.\left(\mathrm{SiO}_{4}\right)_{3}(\mathrm{O}, \mathrm{OH})_{3}\right)$.

Qz2 comprises $20-100 \mathrm{ppm} \mathrm{Ti}$ and $\mathrm{Al}$ is max $50 \mathrm{ppm}$ (Fig. 11a). Qz2 in amphibolite hosted quartz veins has higher Ti than Qz2 in quartzite (Fig. 11a) but $\mathrm{Ti}$ is randomly distributed (Fig. 11c), whereas $\mathrm{Ti}$ in Qz2 in quartzites varies normally around $32 \mathrm{ppm}$ (Fig. 11c). Qz2 and Qz3 are consistently low in Al (Fig. 11a, d). Qz3 has trace element content close to or below the detection limits (Fig. 11a, c, d). In addition Qz3 features almost the same chemistry in both amphibolite and quartz veins and in quartz-muscovite veins.

\section{Discussion}

The properties of quartz vary significantly between quartz types and are related to the defect structure as indirectly documented by SEM-CL.

Quartz in this study features variable rheological behaviour as a function of recrystallisation. In addition the fluid flow pattern in shearzones is well preserved by the quartzites. In the next sections the role of fluids and the importance of spatial and temporal fluid availability in quartz deformation, recrystallisation and trace element mobilisation are discussed. It is demonstrated that high 
Fig. 7 Optical and SEM-CL textures from 03bes32, locality 1. a Large scale SEM-Cl textures from part of 03bes 32 , showing relation between Qz1 and Qz2 (main proportion) both intersected by Qz3. Note that grain boundary depends on quartz type, i.e. Qz2-Qz2 boundaries are straight suggesting equilibrium whereas Qz2-Qz1 boundaries are irregular with pinning, dragging and window microstructures suggesting growth of Qz2 at the expense of Qz1. b Ilmenite partly altered to rutile, most altered grain related to Qz2, whereas well preserved ilmenite grain relates to $\mathrm{Qz} 1$
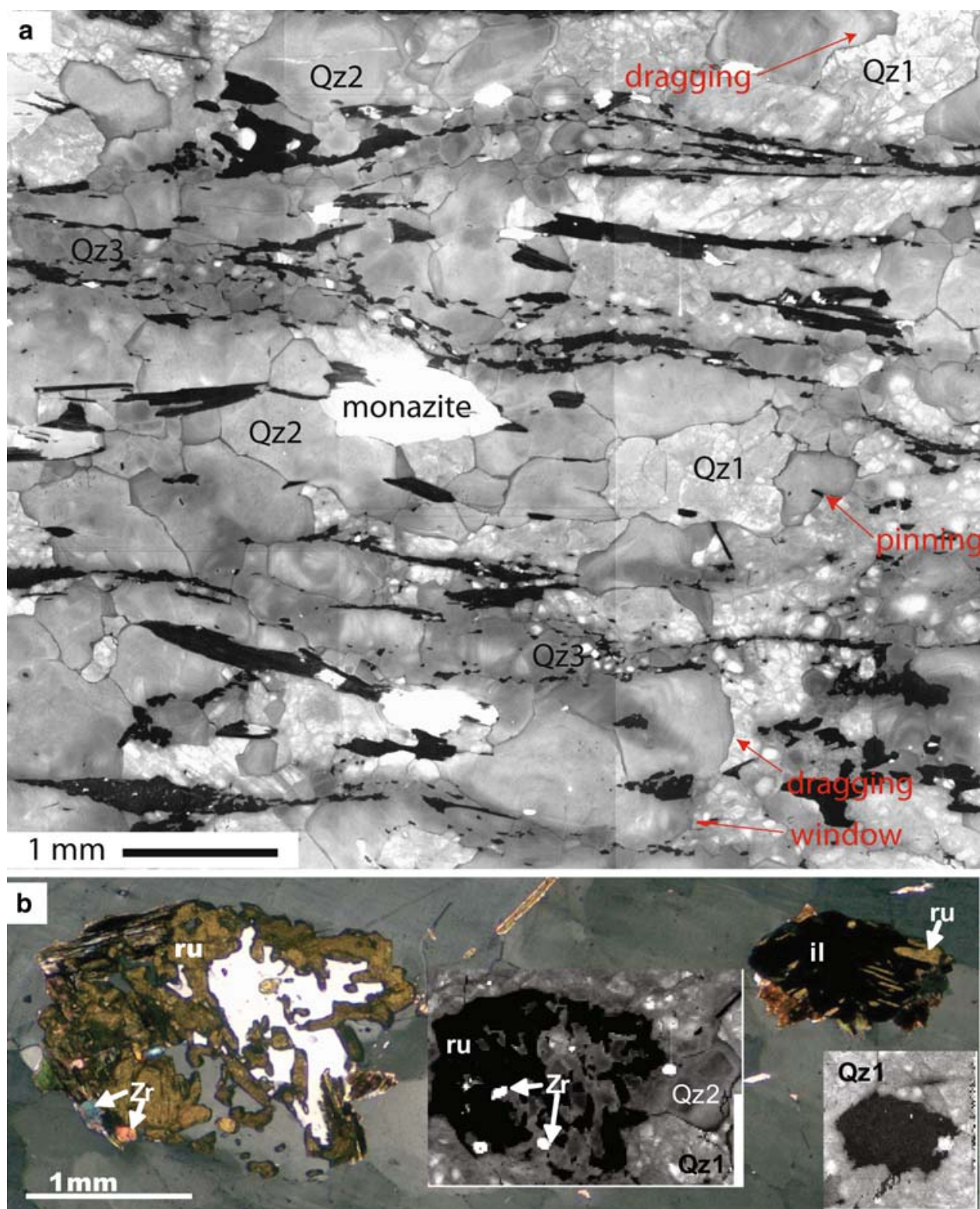

grade quartz survives during the retrograde metamorphic evolutions at fluid absent conditions, whereas quartz subjected to aqueous fluids at the same conditions is chemically and texturally altered.

\section{Textural chronology}

Four main types of quartz occur in quartzites and quartz veins. Different degrees of luminescence darkening connect one type of quartz to later generations, i.e. channels in Qz1 match the luminescence level in Qz2. Qz1 grains are the raw material to Qz2. Qz3 textures always intersect Qz1 and Qz2 textures hence are younger. Luminescence reduction textures related to the Qz3 comprise several subtypes:
Loss of luminescence intensity (Qz3) occurs along grain boundaries between Qz1 and Qz2, and Qz2 and Qz2. This type of Qz3 is in optical continuity with the Qz2 grains, i.e. on the Qz2 side of the grain boundary, suggesting that Qz1 was consumed during this process. However, diffuse channels of Qz3 intersects both Qz1 and Qz2, but are more common in Qz2.

Together, the relative chronology may be summarised to:

Qz1: bright islands surrounded by narrow darker cracks. Qz2: light grey quartz with the same grey level as the channels in Qz1; occasionally with oscillatory zoning. Qz3: dark grey diffuse channels intersecting Qz1 and Qz2. Qz4: black to very dark grey luminescent quartz. 

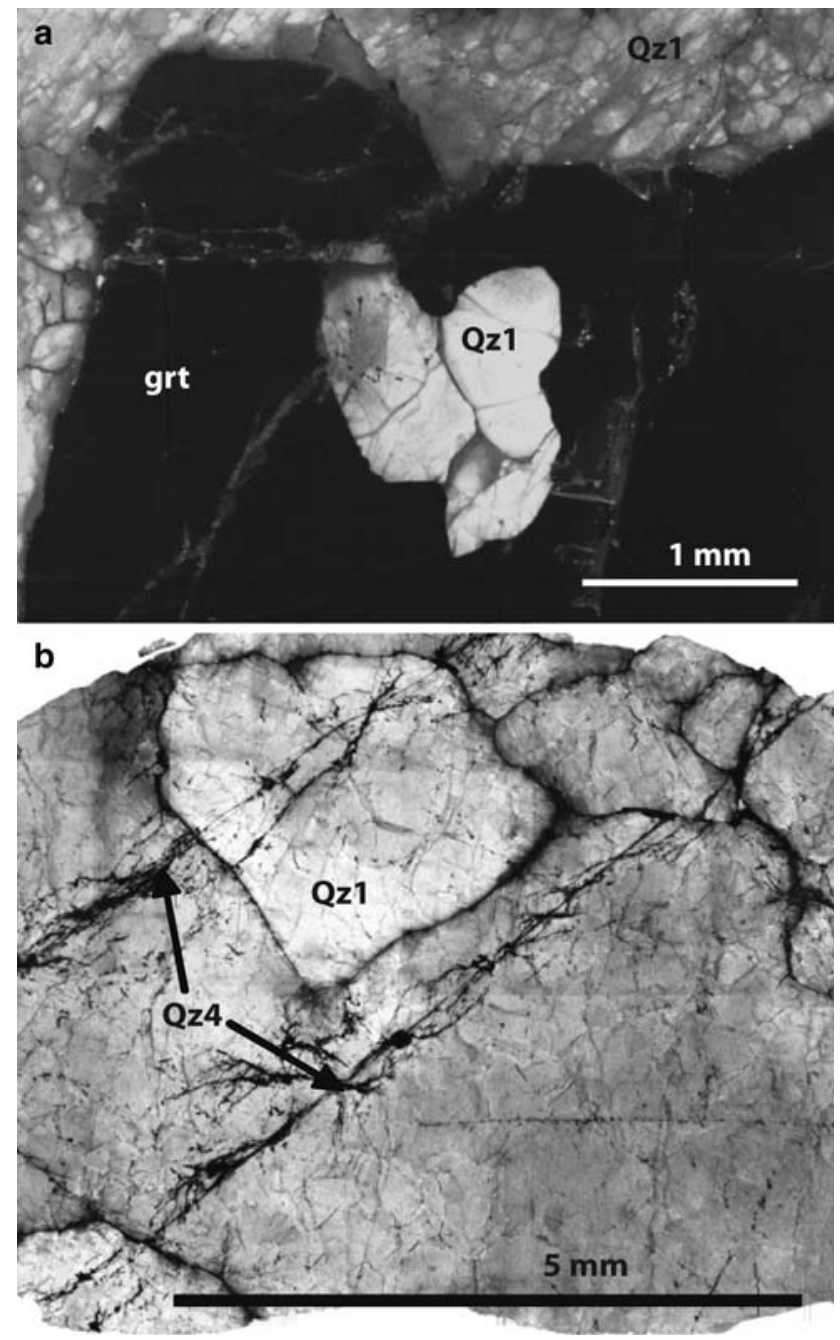

Fig. 8 Optical and SEM-CL textures from garnet quartz symplectites, rose quartz veins (locality 3 ). a SEM-CL image showing bright Qz1 inclusions in garnet and less bright and more cracked Qz1 and Qz2 outside garnet. b SEM-CL image of rose quartz vein, consisting of Qz1, cut by trans- and circum-granular cracks of Qz4

\section{Patterns of recrystallisation}

Quartz shows similar textural types regardless of the lithological setting. The presence of aqueous brines in Qz2 (Sørensen 2007), the island texture in Qz1 and the oscillatory zoning in Qz2 imply that brecciation associated with dissolution and re-precipitation is responsible for the formation of Qz2. Experiments demonstrate that only small quantities of water are required to lower the creep strength of quartz (e.g. Kronenberg and Tullis 1984; Kronenberg 1994), whereas larger amounts in excess of $0.2 \mathrm{wt} \%$ facilitate brecciation of the quartz (e.g. den Brok and Spiers 1991; Post and Tullis 1998). Accordingly, the brecciation in the study area must be the result of aqueous fluid infiltration in dry high grade quartz (Fig. 12).
Qz1 features increased luminescence toward high strain areas accompanied by changes in the subgrain structures from chess board to basal type subgrains. Thus, the increased luminescence intensity in Qz1 relates to plastic deformation associated with basal slip deformation at low recovery rates resulting in increased defect density. This matches observations in experimentally deformed vacuum dried quartzites (see Kronenberg 1994 and references therein).

Qz3, on the contrary, features strong evidence of recovery by the formation of new smaller grains, typical of SGR (subgrain rotation recrystallisation) processes within the high strain areas. Experimentally, these features relate to deformation of quartzites at water saturated conditions, i.e. homogeneous distributions of both basal and prismatic dislocations and organised dislocation configurations (see Kronenberg 1994 and references therein). Accordingly the rheology of Qz3 formed in response to aqueous fluid infiltration and indeed Qz3 hosts primary highly saline aqueous inclusions (Sørensen 2007). The introduction of water increased the plasticity and also enhanced the local recovery rate (Fig. 12) hence, facilitating continuous dislocation climb and lowered the work hardening.

The increased recovery and healing rates caused by the infiltrating aqueous fluids during deformation also refined the quartz under the formation of of high purity quartz (i.e. $<40 \mathrm{ppm}$ impurities). Probably, fluid infiltration followed minute cracks associated with larger fractures in a horse tail pattern (Fig. 12). High salinities provide fluids with a very good wetting capability against quartz (Watson and Brenan 1987) hence enabling fluid flow in narrow submicroscopic cracks. The smaller grain size in Qz3 increased the permeability in Qz3-rich domains. Therefore, fluids were focused in high strain ductile areas as they percolated through the fault system simultaneously with the cracking process propagating through less ductile Qz1 and Qz2 (Fig. 12). TEM observations document close association between dislocations and nano-inclusions of $\mathrm{H}_{2} \mathrm{O}$ in quartzites naturally and experimentally deformed at high $\mathrm{PH}_{2} \mathrm{O}$. This suggests that water travelled along grainand subgrain boundaries during deformation assisted recovery (see Kronenberg 1994 and references therein). Thus, both intra- and intergranular water participated in the quartz recovery process on a localised scale sustaining the differential behaviour of the quartz types. This agrees with other studies where fluid inclusion water in shear zones correlates with localised high shear strains (e.g. Kronenberg et al. 1990; Nakashima et al. 1995).

The ductility and the recovery rate may be influenced by the presence and speciation of trace elements in the quartz structure. This is because, included trace elements may serve as obstacles for propagating dislocation loops during dislocation glide and obstruct climbing dislocations hence, 
Fig. 9 SEM-CL textures of quartz vein associated with potassic alteration of amphibolite. a SEM-CL of 04bes120 sample related to potassic alteration with black amphibole and biotite (field colours). Quartz mostly consists of Qz1 with minor amounts of Qz2 and Qz3. b Optical image of same area in 04bes120. Note chess board texture overprinted by elongated prismatic subgrains in the lower part of the middle Qz1 grain, In the corresponding SEM-CL picture (a) this shift in the microstructure is also detected. Note that the luminescence increases as the prismatic subgrains become more pronounced. c SEM-CL textures in quartz vein (04bes91, locality 5 ), surrounded by potassic alteration with bleached actinolite and light brown biotite (field colour). The contrast setting in the SEM was increased, compared to the other samples to see the textures in this sample, which generally are low luminescent. The difference between Qz1 and Qz2 is small but may be differentiated by the barely recognisable cracked texture of Qz1 and the faint oscillatory zoning in Qz2. Qz3 in this sample display a partly connected channel network. Qz4 occurs as cracks in the large Qz1 grain to the right and along grain boundaries
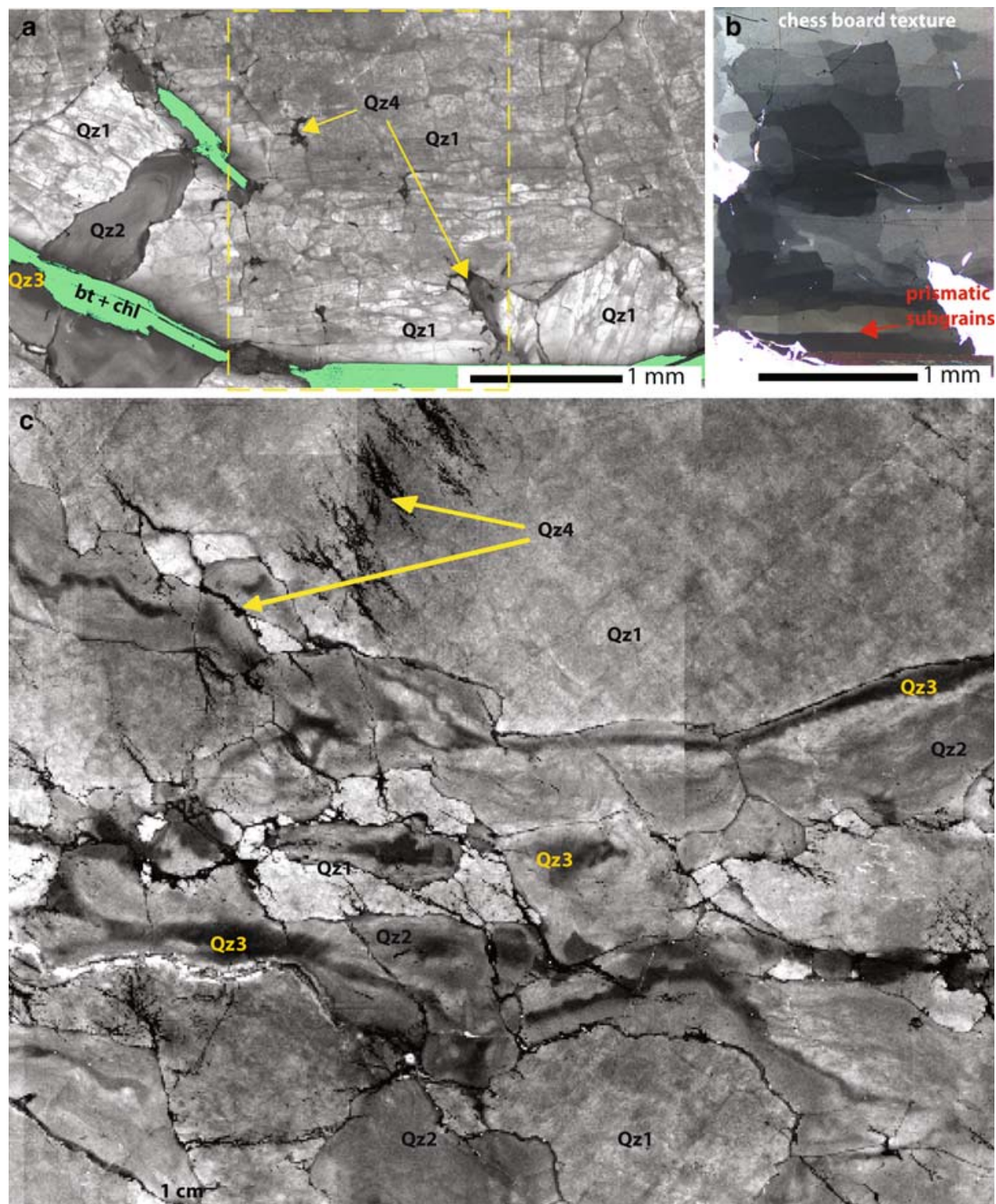

making dislocation glide and recovery through dislocation climb less efficient.

Straight boundaries and triple junctions between Qz2 grains and interlobate-lobate contacts between Qz1 and Qz2 suggest that different processes controlled the geometry of the grain boundaries. Qz2-Qz2 boundaries are explained by energy minimisation by GBAR (grain boundary area reduction) whereas Qz1-Qz2 boundaries formed by GBM (Grain Boundary Migration)(e.g. Passchier and Trouw 2005). Pinning, window, dragging and "left over grain" microstructures (see e.g. Jessell 1987; Passchier and Trouw 2005 for definitions) documents that Qz2 grains grew at the expense of Qz1 grains. The GBM process is driven by contrasting dislocation densities between grains, i.e. grains with high dislocation densities consume grains with lower dislocation densities in order to minimise the free energy of the system (e.g. Passchier and Trouw 2005). The high defect concentration in Qz1 is documented by the high and uneven SEM-CL of Qz1 compared to Qz2. Therefore, SEM-CL could become an important tool to improve the understanding of the poorly understood GBM process in quartz tectonites.

\section{Trace element distribution and behaviour}

Both Qz1 and Qz2 have contrasting trace chemical signatures. Qz1 has much higher and more variable Al and B contents than the other quartz types. Most of the $\mathrm{Al}$ and $\mathrm{B}$ in Qz1 are included in nano scale dumortierite, because the $\mathrm{B}$ versus $\mathrm{Al}$ trend match the molar $\mathrm{B} / \mathrm{Al}$ ratio in dumortierite (Fig. 11). This is also reflected by pink quartz being richer in $\mathrm{B}$ and $\mathrm{Al}$ than blue quartz since pink coloured 


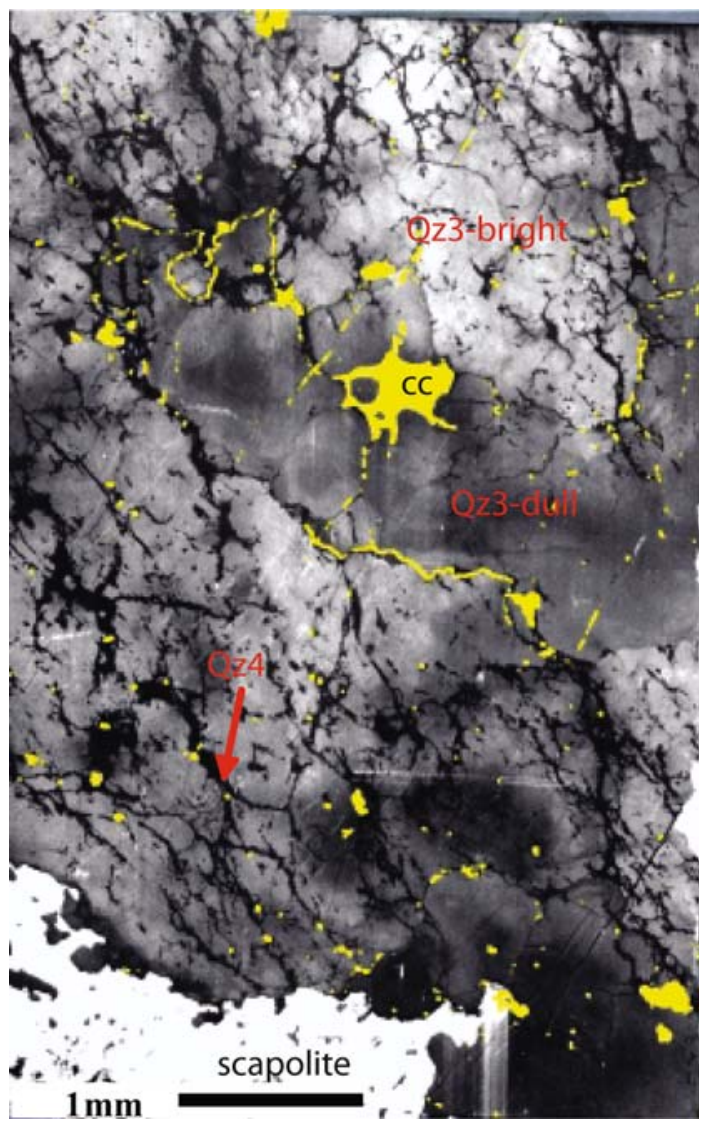

Fig. 10 Optical and SEM-CL textures in quartz scapolite vein. The contrast of in the SEM was amplified, compared to the other samples in this paper in order to image the textures in this sample which generally is low luminescent. Note luminescence quenching next to the Scapolite. Both the light grey and dark grey quartz in this image are classified as Qz3 by comparing with luminescence of other samples. Qz3 is cut by irregular trans- and circumgranular cracks with Qz4. Yellow patches marking calcite inclusions detected by optical microscopy all correlate with Qz4 cracks

dumortierite actually may be the origin of some rose quartz varieties (Applin and Hicks 1987; Goreva et al. 2001).

Contrasting SEM-CL between Qz1 and Qz2 probably is a direct or indirect effect of different concentrations of lattice bound $\mathrm{Ti}$ (Fig. 11). This is supported by the Mono SEM-CL spectra in that Qz1 is dominated by a strong suspected Ti-peak $(450 \mathrm{~nm})$ and a smaller $\mathrm{H}_{2} \mathrm{O} /$ intrinsic peak (620-650 nm) and vice versa in Qz2 (Fig. 3). This overall correlation is somewhat clouded by variable content of coarse rutile needles in Qz2 commonly included in the LA-analysis, causing Ti-bulk variations from 20 100 ppm (Fig. 11). However, in quartzite, rutile needles could be avoided and $\mathrm{Ti}$ in Qz2 displays a normal distribution around $32 \mathrm{ppm}$. The textural correlation between the formation of Qz2 and breakdown of ilmenite to rutile in quartzites document that rutile was stable together with Qz2, hence enabling rutile quartz thermometry. Rutile quartz geothermometry (Wark and Watson 2006) gives a formation temperature of about $626^{\circ} \mathrm{C}$ for Qz2 using the $32 \mathrm{ppm}$ mode value, hence placing the formation of Qz2 shortly after peak metamorphism at $750^{\circ} \mathrm{C}$ (Nijland and Maijer 1993).

Qz3 is very low in most trace elements including $\mathrm{Al}, \mathrm{Ti}$, and $\mathrm{B}$ and has low luminescence. The destabilisation of rutile aided to create quartz that was also pure on the bulk scale, because this prohibited rutile quartz intergrowths.

Implications for mega shearzone fluid migration

The recrystallisation history recorded by the quartzites documents the fossilised plumbing system that accommodated fluid fluxing from deep seated to shallow parts of the Bamble shear zone complex. The observed differential behaviour of quartz during fluid infiltration into a dry protolith uncovers some important aspects of fluid migration in inter-crustal shearzones. Fluid flow in shearzones is associated with hydrolytic weakening and large scale element mobility.

The formation of Qz3 is associated with the decomposition of biotite to poikiloblastic muscovite hence, implies massive $\mathrm{Mg}$ and $\mathrm{Fe}$ mobilisation along fluid channel microstructure of Qz3 fingering through Qz1 and Qz2.

Qz2 associates with $\mathrm{Fe}$ removal from ilmenite during the formation of rutile. The fact that the same quartz-types and textures occur over a relatively large area in different lithologies imply the semi-regional impact of fluid flow and element mobility even in ductile shearzones.

Elements are typically redeposited in the vicinity of shearzones, in second or third order faults. Accordingly, the quartz evolution documents how deep crustal shearzones like the Bamble mobile belt serve as fluid conduits providing large scale mass transport. Particularly the grain size reduction in high strain domains (i.e. Qz3) increases the permeability.

Once fluid infiltration during focused high strain deformation is initiated, it may continue as a self-sustained process as long as a fluid supply is available. If, however, fluid supply ceases, quartz may return to intermediate strength and seal up the system. Qz2 formed at $626^{\circ} \mathrm{C}$ thus far above the equilibration limit for normal crustal residence times of $450^{\circ} \mathrm{C}$ (Post and Tullis 1998) and the textures document that full fluid flow was transient in nature. Accordingly, the limited fluid supply may be the primary control of recrystallisation to stable mineral assemblages, i.e. recrystallisation did not occur at the thermodynamic equilibrium boundary but far inside the stability field of an assemblage. Consequently, the formation of a given retrograde assemblage is controlled by the presence or absence of fluids. Given this scenario, the contrasting PT-histories of mineral assemblages that sometimes are only centimetres apart may be explained by 
a

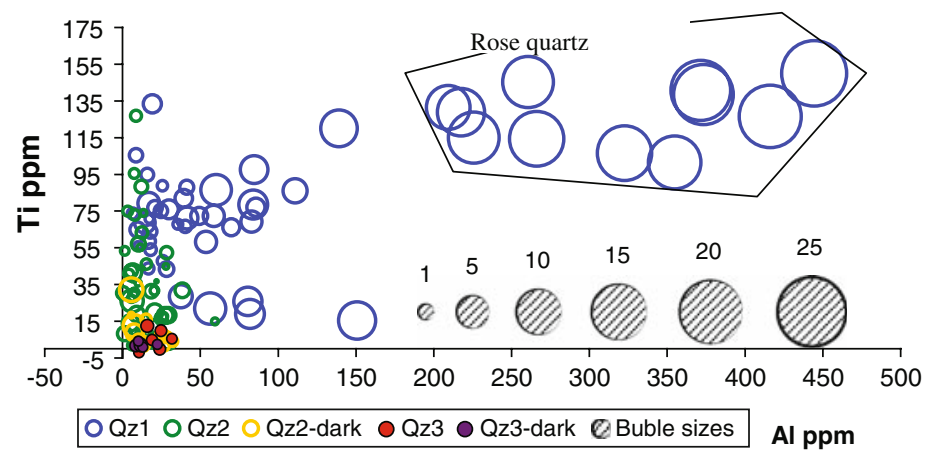

b

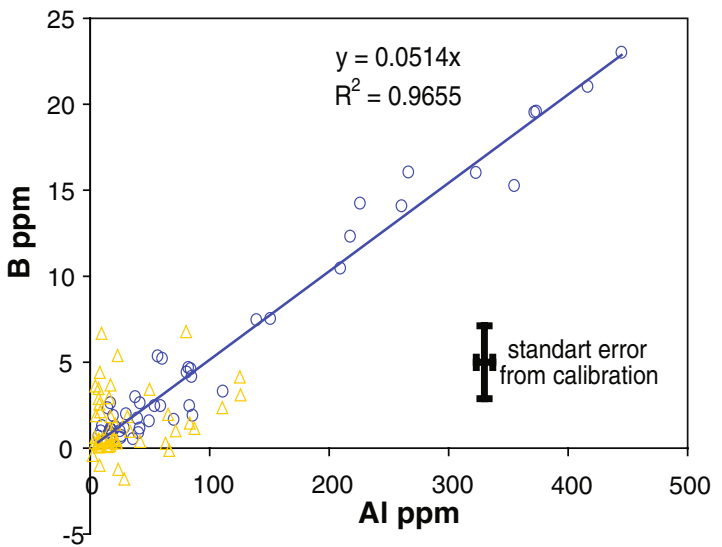

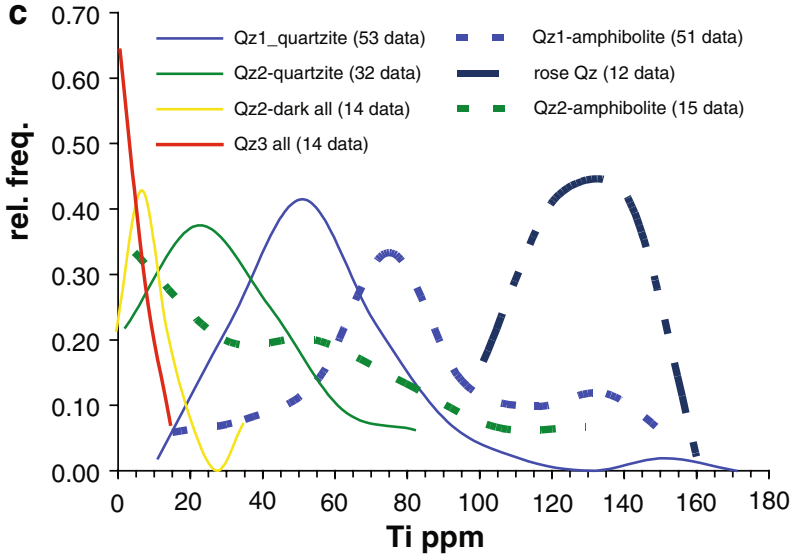

Fig. 11 Trace element distribution in quartz. a Plot of Ti vs. Al with bubble size from boron. b Linear correlation between $\mathrm{Al}$ and $\mathrm{B}$, followed by quartz veins and leucosomes in amphibolite (blue

the flow of fluids in narrow structures separated by "dry" structures as it is documented in our study of quartz types.

\section{Conclusions and summary}

Complex recrystallisation textures in quartz were documented by SEM-CL. Quartz formed at high metamorphic grades under dry conditions, underwent localised recrystallisation during cooling and exhumation. Recrystallisation is associated with two main stages of fluid influx:

1. First introduction of aqueous fluids, comprising a mix of $\mathrm{CO}_{2}$-rich low salinity and $\mathrm{CO}_{2}$-poor $\mathrm{NaCl}-\mathrm{KCl}-\mathrm{H}_{2} \mathrm{O}$ $\mathrm{CO}_{2}$ eutectic salinity brines (Sørensen 2007) that provoked brecciation and dissolution-reprecipitation of quartz. Quartz types Qz2 and Qz1 bear witness to this event; Qz1 represents relics of old brecciated grains characterised by an uneven luminescence pattern comprising islands with bright luminescence surrounded by darker channels. Qz2 represents quartz that was re-precipitated from the brecciation

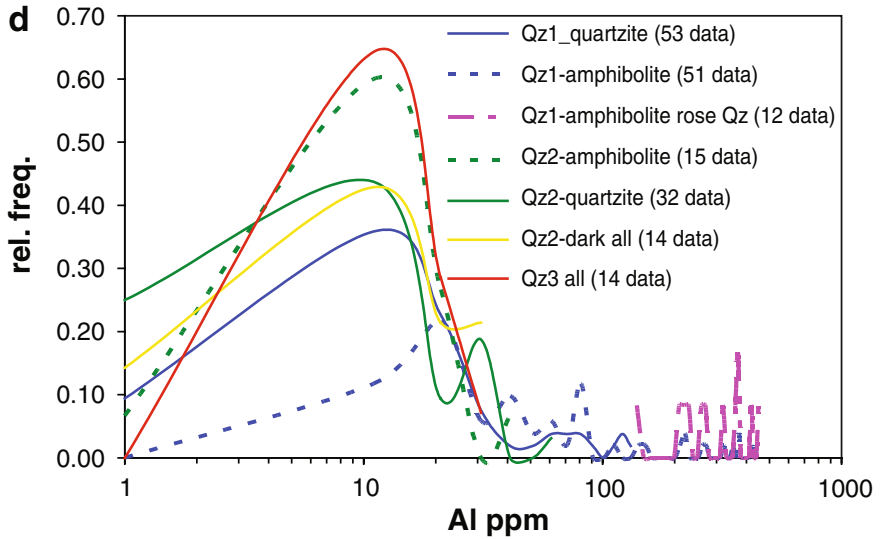

symbols), but not by Qz1 in quartzite (yellow symbols). c Relative frequencies of $\mathrm{Ti}$ content in the different quartz types. d Relative frequencies of $\mathrm{Al}$ content in the different quartz types

dissolution process responsible for the formation of Qz1. Luminescence of Qz2 is more even that of Qz1 but faint oscillatory zoning implies the hydrothermal origin of Qz2. Rutile was the stable Ti-bearing phase during Qz2 formation and formed at the expense of ilmenite. Rutile needles are more abundant in amphibolites hosted Qz2 quartz veins than in quartzite Qz2.

2. Second fluid influx propagated along feather like system of minute cracks. Fluids were $\mathrm{CO}_{2}$ free brines with a good ability to infiltrate quartz due to low wetting angles of brines against quartz. Fluid infiltration facilitated recrystallisation of quartz (Qz3) in $\mathrm{mm}$ wide fluid channels. Qz3 is more plastic than Qz1 and Qz2 during deformation and experienced SGR (Sub Grain Rotation recrystallisation). Increased SEM-Cl intensity in Qz1 toward zones in which Qz3 experienced SGR testify to increased dislocation densities related to strain hardening processes in Qz1. Qz3 is texturally correlated with the decomposition of rutile to titanite. Qz3 correlate with thrust related microstructures. Fluid inclusion studies document the fluid in equilibrium with Qz3 to be brine with $25 \mathrm{wt} \% \mathrm{NaCl}$ 
Fig. 12 Patterns of recrystallisation as demonstrated by SEM-CL and optical microscopy. a Homogeneous quartz at high metamorphic grade. $\mathbf{b}$ Introduction of aqueous fluids under differential stress induces brecciation. c Quartz dissolved during brecciation precipitates as Qz2, Qz1 is the brecciated old grains. d Repeated deformation induces fracturing. e Infiltrating aqueous fluids move along the fractures causing recrystallisation $(\mathrm{Qz} 3)$, but also promoting crack mobility. $f$ The recrystallised quartz (Qz3) is more plastic than Qz1 and Qz2 and deform by SGR (subgrain rotation recrystallisation). Continuous fluid flow through the more finegrained Qz3 domains increase recovery rates and reduce strain hardening. Crack propagation and recrystallisation continues and the amount of Qz3 increases

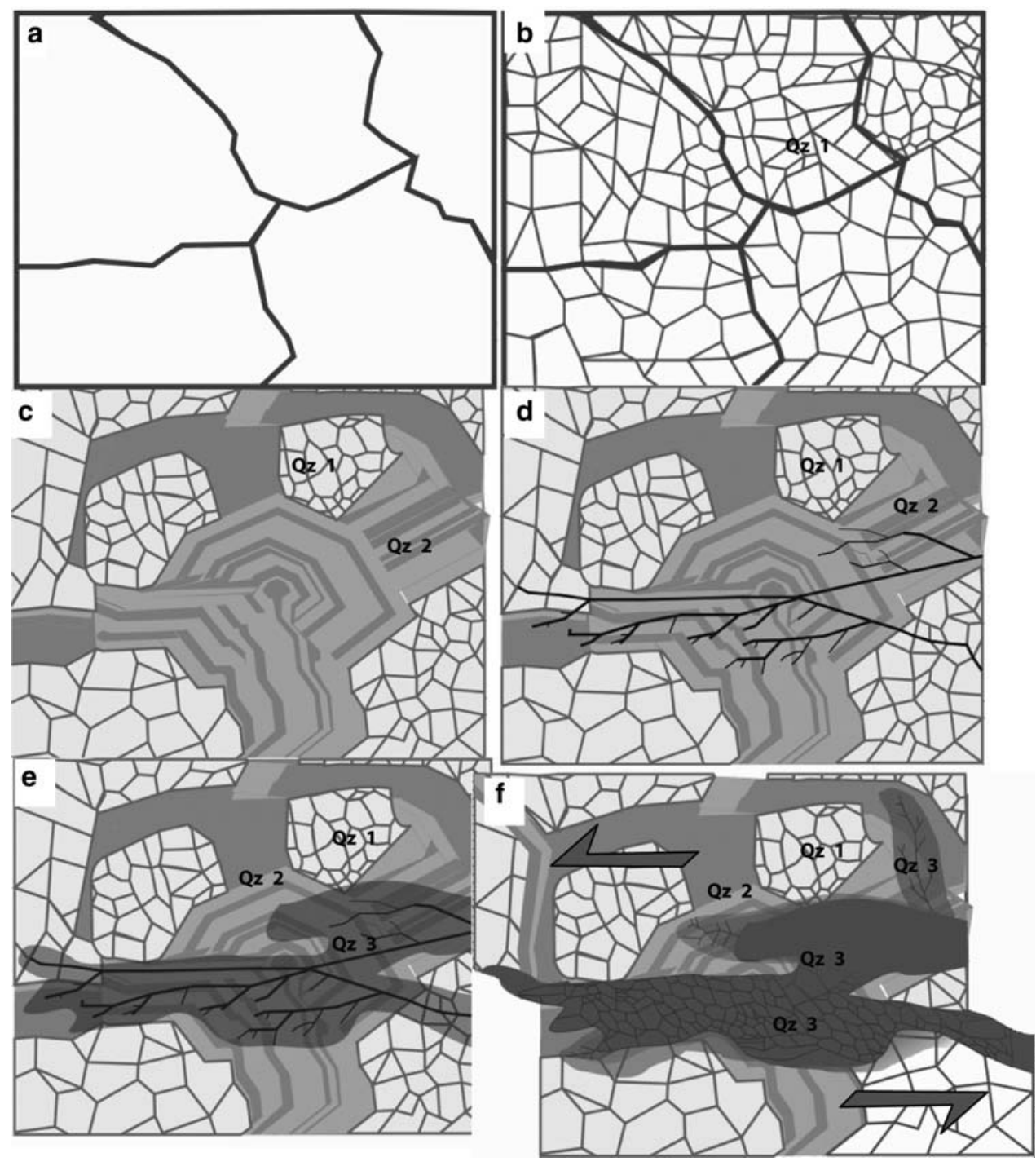

and $6 \mathrm{wt} \% \mathrm{CaCl}_{2}$ (Sørensen 2007). Fluid inclusion isochores along with the trust related microstructures places Qz3 formation during exhumation at 300$400^{\circ} \mathrm{C}$, 3-6 kb (Sørensen 2007). Several later fluid influxes caused localised quartz recrystallisation along micron fractures $(\mathrm{Qz} 4)$.

Trace elements in quartz were gradually removed from the quartz lattice during retrograde recrystallisation and are correlated with lowering of luminescence intensity.

$\mathrm{Ti}$ along with intrinsic- and water related defects is probably responsible for the luminescence observed in our samples and undergoes a progressive depletion during retrograde recrystallisation:

- Qz1 is richest in structurally bound Ti.

- Qz2 is lower in structurally bound Ti but contains numerous rutile needles. They formed as intergrowths because rutile was the stable $\mathrm{Ti}$ phase during Qz2 formation. Qz2 in quartzite average $32 \mathrm{ppm}$ Ti.
- Qz3 is low in Ti and also in other trace elements. This is partially due to a low abundance of structurally bound trace elements, but the destabilisation of rutile in relation to Qz3 served to produce quartz with a uniform low bulk Ti concentration below 5 ppm.

Our study underlines the importance of fluids on quartz rheology. This is demonstrated by the differential behaviour of Qz1, Qz2 and Qz3 during deformation. During uplift, Qz3 deformed plastically and recovered by SGR. At the same time Qz1 experienced strain hardening caused by accumulation of dislocations demonstrated by increased cathodoluminescence intensity. In agreement with experimental studies we infer that the increased plasticity and recovery rate in Qz3 was caused by increased $\mathrm{H}_{2} \mathrm{O}$ contents of the fluid. This interpretation is substantiated by the record of fluid inclusions in Qz3 by Sørensen (2007). However, it is also suggested that trace elements in quartz may affect the rheological properties as trace elements in the quartz lattice 
may obstruct dislocation glide as well as dislocation climb hence promoting strain hardening and fracturing.

Grain boundary geometries are also partially controlled by the trace element contents. Qz1-Qz2 grain boundaries are interlobate-lobate. Qz2 grew at the expense of Qz1 during GBM, whereas Qz2-Qz2 boundaries are straight with common triple junctions implying static recrystallisation dominated by GBAR.

Our results demonstrate the importance of narrow fluid pathways in quartzite lithologies in shearzones. Areas highly affected by metasomatism are juxtaposed with apparently unaffected areas millimetres or microns away. The transient nature of fluids migration through the crust will generate local variations in the timing of fluid flow. The availability of fluid will control the formation of retrograde mineral assemblages hence areas that underwent the same PT-history may record different PT-histories through their mineral assemblages.

Acknowledgments Arild Monsøy and Kjetil Eriksen at the thin section laboratory at The Department of Geology and Minerals Engineering, Norwegian University of Technology and Science (NTNU) are thanked for patiently having prepared dozens of carefully polished thin sections. Belinda Flem and Øyvin Skår at the Geological Survey of Norway (NGU) are acknowledged for their assistance with LA-HR-ICP-MS analyses at NGU. John Rasmus Leinum, Tor Arrild Nilsen, Kari Moen and Jarle Hjelen at NTNU are acknowledged for assisting with the SEM-equipment at NTNU. This study was financed by the NFR grant to the Strategic University Program entitled "The value chain from mineral deposit to beneficiated product with emphasis on quartz".

Open Access This article is distributed under the terms of the Creative Commons Attribution Noncommercial License which permits any noncommercial use, distribution, and reproduction in any medium, provided the original author(s) and source are credited.

\section{References}

Applin KR, Hicks BD (1987) Fibers of dumortierite in quartz. Am Mineral 71:786-794

Armington AF, Balascio JF (1984) The growth of high purity, low dislocation quartz. In: Proceedings of the 38th annual frequency control symposium, vol., USA, pp 3-7

den Brok B, Spiers CJ (1991) Experimental evidence for water weakening of quartzite by microcracking plus solution-precipitation creep. J Geol Soc London 148:541-548. doi: 10.1144/gsjgs.148.3.0541

Flem B, Larsen RB, Grimstvedt A, Mansfeld J (2002) In situ analysis of trace elements in quartz by using laser ablation inductively coupled plasma mass spectrometry. Chem Geol 182(2-4):237247. doi:10.1016/S0009-2541(01)00292-3

Goetze J, Plotze M, Habermann D (2001) Origin, spectral characteristics and practical applications of the cathodolumimescence (CL) of quartz-a review. Mineral Petrol 71(3-4):225-250. doi: 10.1007/s007100170040

Goetze J, Ploetze M, Graupner T, Hallbauer DK, Bray CJ (2004) Trace element incorporation into quartz; a combined study by
ICP-MS, electron spin resonance, cathodoluminescence, capillary ion analysis, and gas chromatography. Geochim Cosmochim Acta 68(18):3741-3759. doi:10.1016/j.gca.2004.01.003

Goetze J, Ploetze M, Trautmann T (2005) Structure and luminescence characteristics of quartz from pegmatites. Am Mineral 90(1):13 21. doi:10.2138/am.2005.1582

Goreva JS, Ma C, Rossman GR (2001) Fibrous nanoinclusions in massive rose quartz: the origin of rose coloration. Am Mineral 86:466-472

Griggs DT, Blacic JD (1965) Quartz: anomalous weakness of synthetic crystals. Science 147(3655):292-295. doi:10.1126/ science.147.3655.292

Harlov DE (2000) Titaniferous magnetite-ilmenite thermometry and titaniferous magnetite-ilmenite-orthopyroxene-quartz oxygen barometry in granulite facies gneisses, Bamble sector, SE Norway; implications for the role of high-grade $\mathrm{CO}_{2}$-rich fluids during granulite genesis. Contrib Mineral Petrol 139:180-197. doi:10.1007/PL00007670

Jacamon F (2006) The significance of textures and trace element chemistry of quartz with regard to the petrogenesis of granitic rocks. Dissertation, Faculty of Engineering Science and Technology, Department of Geology and Mineral Resources Engineering, Norwegian University of Science and Technology, Trondheim

Jessell MW (1987) Grain-boundary migration microstructures in a naturally deformed quartzite. J Struct Geol 9(8):1007-1014. doi: 10.1016/0191-8141(87)90008-3

Knudsen TL (1996) Petrology and geothermobarometry of granulite facies metapelites from the Hisøy-Torungen area, South Norway: new data on the Sveconorvegian P-T-t path of the Bamble sector. J Metamorph Geol 14(3):267-287. doi:10.1111/j.15251314.1996.00267.x

Kronenberg AK (1994) Hydrogen speciation and chemical weakening of quartz. In: Heaney PJ, Prewitt CT, Gibbs GV (eds) Silica: physical behavior, geochemistry and materials applications, vol 29. Mineralogical Society of America, Washington, DC, pp 123-176

Kronenberg AK, Tullis J (1984) Flow strengths of quartz aggregates: grain size and pressure effects due to hydrolytic weakening. In: Kirby Stephen H, Scholz CH (eds) Chemical effects of water on the strength and deformation of crustal rocks., vol 89: 6 . American Geophysical Union, Washington, DC, United States, pp 4281-4297

Kronenberg AK, Kirkby SH, Aines RD, Rossman GR (1986) Solubility and diffusional uptake of hydrogen in quartz at high water pressures: implication for hydrolytic weakening. J Geophys Res B Solid Earth Planets 91:12723-12744. doi: 10.1029/JB091iB12p12723

Kronenberg AK, Segall P, Wolf GH (1990) Hydrolytic weakening and penetrative deformation within a natural shear zone. In: Duba AG, Durham WB, Handin JW, Wang Herbert F (eds) The brittle-ductile transition in rocks, vol 56. American Geophysical Union, Washington, DC, pp 21-36

Landtwing MR, Pettke T (2005) Relationships between SEMcathodoluminescence response and trace-element composition of hydrothermal vein quartz. Am Mineral 90(1):122-131. doi: 10.2138/am.2005.1548

Larsen RB (2004) Distribution and petrogenetic behaviour of trace elements in granitic pegmatite quartz. Geochim Cosmochim Acta 68(11):A667-A667

Müller A, Lennox P, Trzebski R (2002) Cathodoluminescence and microstructural evidence for crystallisation and deformation processes of granites in the eastern lachlan fold belt (se austia). Contrib Mineral Petrol 143:510-524

Müller A, Wiedenbeck M, Van den Kerkhof AM, Kronz A, Simon K (2003) Trace elements in quartz: a combined electron 
microprobe, secondary ion mass spectrometry, laser-ablation ICP-MS, and cathodoluminescence study. Eur J Mineral 15(4):747-763. doi:10.1127/0935-1221/2003/0015-0747

Nakashima S, Matayoshi H, Yuko T, Michibayashi K, Masuda T, Kuroki $\mathrm{N}$ et al (1995) Infrared microspectroscopy analysis of water distribution in deformed and metamorphosed rocks. In: Spiers CJ, Takeshita T (eds) Influence of fluids on deformation processes in rocks, vol 245. Elsevier, Amsterdam, pp 263-276

Nijland TG, Maijer C (1993) The regional amphibolite to granulite facies transition at Arendal, Norway: evidence for a thermal dome. Neues Jahrb Miner Abh 165:191-221

Nijland TG, Touret JLR (2001) Replacement of graphic pegmatite by graphic albite-actinolite-clinopyroxene intergrowths (Mjavatn, southern Norway). Eur J Mineral 13(1):41-50. doi:10.1127/ 0935-1221/01/0013-0041

Nijland TG, Liauw F, Visser D, Maijer C, Senior A (1993a) Metamorphic petrology of the Froland corundum-bearing rocks: the cooling and uplift history of the Bamble sector, South Norway. Bull Nor Geol Unders 424:51-63

Nijland TG, Maijer C, Senior A, Verschure RH (1993b) Primary sedimentary structures and composition of the high-grade metamorphic Nivelda quartzite complex (Bamble, Norway), and the origin of nodular gneisses. Proceedings of the Koninklijke Nederlandse Akademie van Wetenschappen (1990) 96(2):217-232

Nijland TG, Touret JLR, Visser D (1998) Anomalously low temperature orthopyroxene, spinel, and sapphirine occurrences in metasediments from the Bamble amphibolite-to-granulite facies transition zone (South Norway); possible evidence for localized action of saline fluids. J Geol 106(5):575-590

Passchier CW, Trouw RAJ (2005) Microtectonics. 2 ed, vol. Springer, Berlin, Federal Republic of Germany, pp 366

Post A, Tullis J (1998) The rate of water penetration in experimentally deformed quartzite: implications for hydrolytic weakening. In: Chester Fred M, Engelder T, Shimamoto T (eds) Rock deformation; the Logan volume., vol 295; 1-2. Elsevier, Amsterdam, Netherlands, pp 117-137

Post AD, Tullis J, Yund RA (1996) Effects of chemical environment on dislocation creep of quartzite. J Geophys Res B Solid Earth and Planets 101(10):22,143-122,155
Sørensen BE (2007) Metamorphic refinement of quartz under influence of fluids during exhumation with reference to the metamorphic/metasomatic evolution observed in amphibolites: a detailed field, microtectonic and geochemical study from the Bamble sector, South Norway. In: Department of Geology and Mineral Ressources Engineering. Dissertation, at Norges teknisknaturvitenskapelige universitet, Fakultet for ingeniørvitenskap og teknologi, Trondheim, pp 215. http://www.diva-portal.org/diva/ getDocument?urn_nbn_no_ntnu_diva-1563-1_fulltext.pdf

Touret J (1968) The Precambrian metamorphic rocks around the Lake Vegår (Aust-Agder, southern Norway), vol 257, pp 45

Touret J (1971) Le faciès granulite en Norvège méridionale II Les inclusions fluides. Lithos 4:423-436. doi:10.1016/0024-4937(71) 90125-3

Touret J (1985) Fluid regime in southern Norway: the record of fluid inclusions. In: Tobi AC, Touret J (eds) The deep Proterozoic crust in the North Atlantic Provinces vol 158, pp 517-549

Touret J, Olsen SN (1985) Fluid inclusions in migmatites. In: Ashworth JR (ed) Migmatites, vol. Shiva, Glasgow, pp 265-288

Tullis J (2002) Deformation of Granitic Rocks: Experimental Studies and Natural Examples In: S.-i. Karato and H.-R. Wenk (Editors), Plastic Deformation in Minerals and Rocks. Reviews in Mineralogy. MSA

Van den Kerkhof AM, Kronz A, Simon K, Scherer T (2004) Fluidcontrolled quartz recovery in granulite as revealed by cathodoluminescence and trace element analysis; Bamble sector, Norway. Contrib Mineral Petrol 146(5):637-652. doi: 10.1007/s00410-003-0523-5

Wark D, Watson EB (2006) TitaniQ: a titanium-in-quartz geothermometer. Contrib Mineral Petrol 152(6):743-754. doi:10.1007/ s00410-006-0132-1

Watson EB, Brenan JM (1987) Fluids in the Lithosphere, 1. Experimentally determined wetting characteristics of $\mathrm{CO} 2$ $\mathrm{H} 2 \mathrm{O}$ fluids and their implications for fluid transport, host-rock physical properties, and fluid inclusion formation. Earth Planet Sci Lett 85:496-515 